\title{
EL MEJORAMIENTO DEL HOMBRE DESDE LA PERSPECTIVA NIETZSCHEANA
}

The Human Enhancement from a Nietzschean Perspective

\author{
Jesús Conill-Sancho
}

Universidad de Valencia ${ }^{1}$

RESUMEN: Este artículo muestra la concepción nietzscheana del mejoramiento humano desde la perspectiva de la «Gran Política», que revela una conexión con la idea de la eugenesia de Francis Galton, pero que implica una crítica del concepto darwinista de la selección natural.

Palabras clave: mejoramiento humano - Gran Política - eugenesia

AвSTRACT: This article shows Nietzsche's conception of human enhancement from the perspective of «Great Politics» that reveals a connection with Francis Galton's idea of eugenics, but implicates the criticism of the Darwinist concept of natural selection.

Key words: Human enhancement - Great Politics - Eugenics

\section{MEJORAMIENTO Y EUGENESIA}

Al tratar de la «actualidad e inactualidad de Nietzsche» me ha parecido muy pertinente considerar la cuestión del «mejoramiento» (Besserung), en la perspectiva de Nietzsche, por una parte, por la importancia interna del asunto en el propio pensamiento nietzscheano, pero, por otra parte, por la creciente actualidad del tema en el panorama contemporáneo, tanto por su conexión con la eugenesia ${ }^{2}$ como con el denominado human enhancement (mejoramiento humano) ${ }^{3}$.

1. Este estudio se inserta en los Proyectos de Investigación Científica y Desarrollo Tecnológico HUM2007-66847-C2-01/FISO y FFI2010-21639-C02-01, financiados por el Ministerio de Ciencia e Innovación con Fondos FEDER de la Unión Europea, y en las actividades del grupo de investigación de excelencia PROMETEO/2009/085 de la Generalidad Valenciana.

2. Cf. D. Soutullo, «Eugenesia (ético)», t. I, pp. 811-818; É. Mendes de Carvalho, «Eugenesia (jurídico)», pp. 818-831; F. J. Júdez, «Mejora (ético)», t. II, pp. 1120-1127, en C. M. Romeo Casabona (dir.), Enciclopedia de Bioderecho y Bioética, Cátedra Interuniversitaria de Derecho y Genoma Humano, Fundación BBVA, Universidad de Deusto, Granada: Comares, 2011; A. Cambrón, «La eugenesia y sus sombras», en Diez palabras clave en nueva genética, Estella: Verbo Divino, 2006, pp. 225-295.

3. N. Bostrom y J. Savulescu (eds.), Human Enhancement, New York: Oxford University Press, 2009; J. Savulescu, R. T. Meulen y G. Kahane (eds.), Enhancing Human Capacities, Oxford: WileyBlackwell, 2011; M. Sandel, Contra la perfección. La ética en la era de la ingeniería genética, Barcelona: Marbot, 2007. Asimismo, cf. la página web siguiente: http://www.practicalethics.ox.ac.uk/ncentre.htm. 
Uno de los problemas más acuciantes ante el que se enfrenta el presente y el futuro del pensamiento contemporáneo y, de modo particular, la bioética es el de la eugenesia. De hecho, un buen experto en esta materia, como es Diego Gracia, ya dedicó un capítulo de su libro Ética de los confines de la vida a la "Historia de la eugenesia» $»^{4}$ con anterioridad había abordado los «Problemas filosóficos de la ingeniería genética $»^{5}$. En su trabajo nos muestra este autor la prehistoria de la eugenesia en los clásicos del pensamiento antiguo (Plutarco, Platón, Séneca, Averroes) y del Renacimiento (Campanella y Bacon), la introducción del término «eugenesia» por parte de Francis Galton ${ }^{6}$ y asimismo los principales hitos del programa eugenésico, entendido como mejora genética, desde sus comienzos en el contexto del evolucionismo darwinista y antidarwinista hasta la eugenesia molecular y la ingeniería genética ${ }^{7}$. La historia de la eugenesia muestra la implantación que llegó a tener como programa de investigación, como movimiento social y político, y hasta como ideología, inspiradora de leyes (y prácticas eugenésicas) en diversos países, hasta bien entrado el siglo XX.

$\mathrm{Y}$ es que la eugenesia ha llegado a fascinar a buena parte del pensamiento moderno, como muestra la relevancia que alcanzó en algunas representaciones utópicas, como La nueva Atlántida de Francis Bacon (en 1624), quien confiaba en el creciente poder de la técnica para lograr objetivos tales como los que expresan las siguientes palabras, y que hoy resuenan con renovado vigor:

Prolongar la vida. Devolver la juventud [...]. Retardar el envejecimiento. Curar las enfermedades tenidas por incurables [...]. Aumentar la fuerza y actividad [...]. Transformar la estatura y los rasgos. Aumentar las funciones del cerebro. Fabricar especies nuevas. Trasplantar unas especies en otras [...]. Hacer felices los espíritus y ponerlos en buena disposición ${ }^{8}$.

El debate sobre la eugenesia ha resurgido con creciente energía en los últimos tiempos, debido sobre todo al avance de las biotecnologías ${ }^{9}$. No es este el lugar

4. D. Gracia, «Historia de la eugenesia», en Ética de los confines de la vida, Ética y Vida. Estudios de Bioética, vol. 3, Santafé de Bogotá: El Búho, 1998, pp. 11-28.

5. D. Gracia, «Problemas filosóficos de la ingeniería genética», en J.-R. Lacadena, D. Gracia, M. Vidal y F.J. Elizari, Manipulación genética y moral cristiana, Madrid: Fundación Universitaria San Pablo, 1988, pp. 94-116.

6. F. Galton, Inquiries into Human Faculty ant its Development, London, 1883 (en la biblioteca de Nietzsche).

7. Cf. D. J. Kevles, La eugenesia. ¿Ciencia o utopía?: polémica que dura cien años, Barcelona: Planeta, 1986; L. E. Kay, The Molecular Vision of Life. Caltech, the Rockefeller Foundation, and the Rise of the New Biology, New York: Oxford University Press, 1993.

8. F. Bacon, La Nueva Atlántida, en Utopías del Renacimiento, México: FCE, 1996, pp. 233 ss. (cf. A. Cambrón, «La eugenesia y sus sombras», cit., pp. 225-295).

9. Cf., p. ej., N. Agar, «Liberal Eugenics» y B. Müller-Hill, «Lessons from a Dark and Distant Past», en H. Kuhse y P. Singer (eds.), Bioethics. An Anthology, Oxford: Blackwell, 1999, pp. 171-181 y 182-187, respectivamente; C. Romeo Casabona (ed.), La eugenesia hoy, Granada: Comares, 2000; F. Fukuyama, El fin del hombre. Consecuencias de la revolución biotecnológica, Barcelona: Ediciones B, 2002; A. Buchanan (ed.), Genética y justicia, Madrid: Cambridge Univesity Press, 2002; J. Habermas, El futuro de la naturaleza humana. ¿Hacia una engenesia liberal?, Barcelona: Paidós, 2002; A. Cortina, «Ética de las tecnologías»: Isegoría 27 (2002), 73-89; M. Sandel, Contra la perfección. La ética en la era de la ingeniería genética, Barcelona: Marbot, 2007. 
para entrar en el complejo entramado de las argumentaciones sobre si la optimización genética es equiparable a la educación, o si se pueden distinguir con precisión la eugenesia terapéutica y la perfeccionista, etc., sino de tratar la perspectiva nietzscheana de la eugenesia y del enhancement (el mejoramiento) en el horizonte contemporáneo de la filosofía en relación con la eugenesia y el enhancement (el mejoramiento humano), en concreto, la visión nietzscheana de lo que supuso la innovación de la idea de la eugenesia desde sus comienzos, dado que Nietzsche leyó la obra de Francis Galton y se inspiró en ella para algunas de sus concepciones, como su nuevo modo de entender el progreso del hombre ${ }^{10}$.

La noción de progreso se ha ligado normalmente a la Ilustración. Pero Nietzsche le da un sentido peculiar que parece conectarse con las nuevas corrientes biológicas de su época. ¿Defiende entonces Nietzsche un progreso biológico? ¿O sigue teniendo un significado específicamente histórico? Pero, entonces, ¿no choca con su concepción del «retorno»? Y, por otra parte, ¿̇no tiene el «progreso» también algún sentido moral? Conviene analizar mejor su propuesta de nueva Ilustración y su conexión con la dimensión biológica para comprender la nueva forma de progreso que propone Nietzsche mediante la selección eugenésica. ¿Se abre la posibilidad de un progreso mediante la selección eugenésica desde la perspectiva nietzscheana?

El otro asunto que ha adquirido una creciente actualidad es el de la mejora del hombre, el human enhancement. A diferencia de algunos nuevos defensores de la naturaleza humana como algo sustantivo y firme (Fukuyama, etc.) ${ }^{11}$, el movimiento denominado 'transhumanismo' defiende la mejora del ser humano para alcanzar un estado superior o posthumano. Defiende el aprovechamiento de las oportunidades de mejorar la condición humana y el organismo humano que han abierto las biotecnologías (como la ingeniería genética, la nanotecnología molecular) hasta configurar lo que se ha llamado ya el cyborg. Hay quienes ven esta posición una amenaza a la dignidad humana, como Leon Kass, quien con su «sabiduría de la repugnancia» (inspirada en la heurística del miedo de Jonas) advierte de los peligros deshumanizadores del uso de las tecnologías, pues permite detectar algo perverso que amenaza lo que apreciamos ${ }^{12}$.

En los últimos tiempos se ha reavivado el debate sobre el uso de las biotecnologías para mejorar las capacidades humanas o para modificar la naturaleza biológica de los seres humanos. ¿Hay una naturaleza humana que es preciso preservar? ¿Se convierte el ser humano en creador y señor? ¿Es mala y perversa la tecnología orientada a la mejora, porque atenta contra la dignidad humana, ya que es ilegítimo alterar el orden natural y, por tanto, el orden que por ser natural es de por sí bueno? ¿Es legítimo programar personas, seleccionando o mejorando a los individuos? Por ejemplo, el poder elegir a los hijos o cómo se quiere que sean. Los transhumanistas defienden la capacidad de tomar decisiones sobre la propia vida y el propio cuerpo, conforme al concepto de selfownership. Cada cual es dueño de su propia vida, lo cual enlaza con el principio de autonomía (moral y bioético), así como con la noción de ciudadanía. Si las tecnologías de

10. Cf. M.-L. Haase, «Nietzsche liest Francis Galton»: Nietzsche-Studien 18 (1989), 633-658.

11. F. Fukuyama, El fin del hombre, cit.

12. «The wisdom of repugnance»: The New Republic 22 (1997), citado por Lydia Feito en «Hacia una mejor comprensión del papel de la naturaleza humana en los debates bioéticos»: Veritas 23 (septiembre de 2010), 111-129. 
mejora están a disposición y tenemos la capacidad de ejercer la libertad de elección, entonces podemos decidir utilizar las tecnologías para la propia conformación (libertad morfológica) y para la reproducción (libertad reproductiva), según la información del artículo citado de Lydia Feito.

Julian Savulescu defiende que igual que buscamos mejoras en otros ámbitos, si queremos ser más sanos, más inteligentes, más atractivos, etc., entonces si disponemos de los medios técnicos, no hay razón para no promover mejoras, no se trata de algo inmoral, sino todo lo contrario, aconsejable e incluso obligatorio. Pues es legítimo ofrecer las mejores posibilidades tanto para sí mismos como para los demás (por ejemplo, para los hijos). Además es difícil separar lo que es terapéutico y lo que es mejora, lo que es curar una enfermedad o contribuir a superar una discapacidad y mejorar el bienestar superando el malestar, ya que en último término es muy difícil definir la salud. El propio Savulescu ha defendido el «Principio de Beneficencia procreadora» para seleccionar a los niños que puedan tener mejor vida entre los posibles, los que puedan tener la «mejor vida» posible, el mejor bienestar, a través de los medios biotecnológicos a disposición. La selección se convierte en una posibilidad legítima e incluso en una obligación ${ }^{13}$. ¿Tienen estos planteamientos y propuestas de mejoramiento (enhancement), al igual que las de la eugenesia, resonancias nietzscheanas? ¿Se trata de algún mejoramiento del hombre en sentido nietzscheano?

\section{LA «GRAN POLÍTICA»14}

Según Nietzsche, de la crisis nihilista y a través de la transvaloración surge la necesidad de la "gran política», a fin de generar un nuevo tipo de hombre, capaz de instaurar el sentido y el dominio de la tierra. Tras el gobierno de Dios y de la moral, de la nada en forma de ideal, irrumpe un nuevo sentido y una nueva posibilidad de dominio sobre la tierra.

Nietzsche propone una «nueva interpretación», que significa una «transvaloración de los valores». «¿Cómo tienen que estar constituidos los hombres que valoren de forma inversa? Hombres que posean todas las propiedades del alma moderna pero que sean lo suficientemente fuertes para transmutarlas en pura salud $»^{15}$.

Pero ces posible liberarse de la «enraizada necesidad de interpretar moralmente»? Nos movemos entre interpretaciones, que contienen valores y metas que ofrecen «sentido». La interpretación moral del mundo ha ofrecido un sentido y un valor, pero también un desengaño, de manera que se desconfía del sentido de la existencia y parece que no hay ningún sentido y que todo es «en vano».

La moral ha invertido la «ley de la selección». El pathos de la distancia ofrece un nuevo punto de vista, la perspectiva aristocrática de la autosuperación del hom-

13. J. Savulescu, «Procreative Beneficence: Why We Should Select the Best Children»: Bioethics XV 15-16 (2002), pp. 413-426.

14. J. Conill, El poder de la mentira. Nietzsche y la política de la transvaloración, Madrid: Tecnos, 1997, pp. 158 ss.; N. Bostrom y R. Roache, «Human Enhancement: Ethical Issues in Human Enhancement», en J. Ryberg, T. S. Petersen y C. Wolf (eds.), New Waves in Applied Ethics, Palgrave: MacMillan, 2008 (citados por Lydia Feito).

15. KGW VIII/1 107-108: 2[100] (FP IV 105). 
bre y la creación de valores vitales. Se sienten y se viven la distancia y la soledad, las relaciones de poder. No hay hermandad ni camaradería. No hay igualdad.

La máxima preocupación nietzscheana se centra en la administración de la tierra y en la educación (o cría) del hombre ${ }^{16}$. La tarea es el hombre mismo, en el marco de una 'guerra espiritual' entre interpretaciones valorativas. En uno de sus últimos apuntes de los cuadernos de Nietzsche encontramos un texto con el título «La gran política» ${ }^{17}$, en el que se habla de poder «criar» (züchten) la humanidad como un todo y algo superior, en contra de «toda forma de contranaturaleza». Hay que criar al hombre como «señor de la tierra» y afirmador de la vida.

Pero, ¿qué es la vida ${ }^{18}$ ? Voluntad de poder, aristocracia, jerarquía; ni solidaridad, ni compasión. Pues hay que superar la decadencia y la degeneración de la vida, si se quiere llevar a cabo la cría de la «raza de señores». He aquí la tarea de la nueva paideia, que consiste en educar para la afirmación de la vida y así evitar el «desgarro» que la moralización de la vida ha producido ${ }^{19}$. En este nuevo enfoque se da una reconciliación entre natura y cultura, pues se trata de una cría, pero no de una domesticación o doma represora de los instintos y valores vitales. Y por eso se abre el horizonte de una cultura de la salud. «Cada uno de nosotros desea ser señor en lo posible de todos los hombres, preferiblemente Dios. Esta actitud tiene que seguir existiendo $»^{20}$. Con lo cual, lo que está en juego es un proceso que está abocado, o bien a reproducir un tipo mediocre de hombre, preparado para la esclavitud moderna, o bien a originar 'hombresexcepción', auténticos soberanos.

\section{EL SUPERHOMBRE: MÁS ALLÁ DE LA FELICIDAD}

Frente a la ideología darwinista, para Nietzsche, el problema está en la jerarquía entre tipos humanos, que siempre han existido y siempre existirán. Nietzsche distingue entre «un tipo de vida ascendente y otro de la decadencia» ${ }^{21}$. Tal vez el superhombre sea solo una cara - una perspectiva - de la realidad, un lado del pensamiento abismal del eterno retorno; y el hombre «pequeño» o «último» conformaría la otra cara -otra perspectiva- y por eso la doctrina nietzscheana es ambivalente y plantea el reto de tomar la decisión entre distintos sentidos vitales: el «último hombre» o el «superhombre». Lo importante es darse cuenta de que estos no están en progresión darwinista, sino que forman parte del acontecer en el que todo retorna ${ }^{22}$. El superhombre se revela como un posible sentido - afirmador y meliorativo— de la vida: «el superhombre, el transfigurador de la existencia $»^{23}$. Pero hay

16. KGW VII/ 306: 37[8] (WM \$ 957) (FP III 814-815).

17. KGW VIII/3 25[1], diciembre de 1888-comienzos de enero de 1889; FP IV 773: 25[1]; MBM $\ 208$, p. 150, y H. Ottmann, Philosophie und Politik bei Nietzsche, Berlin: Gruyter, ${ }^{2} 1999$, p. 243.

18. Cf. J. Conill, op. cit., pp. 191 ss.

19. GM II $\$ 23$.

20. KGW VII/2 25[137]; FP III 481: 25[137]; H. Ottmann, op. cit., p. 265.

21. KGW VIII/3 15[120] (primavera de 1888); FP IV 670: 15[120]; MBM $\$ 242 ;$ AC $\$ 4$.

22. Za, pp. 297 ss.

23. FP III 790: 35[73]: el transfigurador o glorificador de la existencia. 
que tener en cuenta que se trata de una forma singular de vida, no una «especie» ${ }^{24}$. Se trata de individuos que saben y pueden dar sentido superior a la vida.

Desde esta perspectiva se critica la modernidad, por haber degenerado al hombre y haberle imposibilitado descubrir dónde está su grandeza, su posible elevación. En el democratismo desaparece la jerarquía natural en función del igualitarismo. El modo de vida moderno favorece el «animal de rebaño», en detrimento de la «persona individual». Al final acaba predominando la «animalización gregaria» en detrimento de la libertad. El hombre libre es un "guerrero", que no se somete a la vida regida por la seguridad y el bienestar, que tiene «voluntad de autorresponsabilidad $»^{25}$. Pero la lógica de la modernidad es decadente y degenerativa, porque impone la «mercantilización del juicio de valor». A ello favorece la lógica de la simplificación informativa, tan cultivada sobre todo por los periodistas, que son los expertos de la simplificación y por cuya mediación va degenerando y empequeñeciéndose la vida. Contribuyen a que la masa imponga su tiranía. El resultado es una esclavitud espiritual, porque cada cual ya no se atreve a ser él mismo ${ }^{26}$. Pero, entonces, ¿̇para qué la democratización, si va contra el individuo soberano?

En cambio, la auténtica «elevación del hombre» llevaría consigo la superación de las interpretaciones estrechas, el cambio de las valoraciones y perspectivas vitales. Ahora bien, la elevación del hombre no consiste en un «mejoramiento» sino en un «fortalecimiento» del tipo hombre, para que no huya ante el carácter inquietante y enigmático del mundo, ni quiera negarlo. Pero ¿dónde encontrar tal fuerza? La fuerza radical que regenerará al hombre está en su interior. Desde ahí brota la fortaleza para sobreponerse a los presuntos «hechos», ya que todo depende de las relaciones que se establezcan a partir de la fuerza interior. Los mismos hechos se pueden interpretar y aprovechar de modos muy diferentes, así que no estarán tan «hechos», sino que dependen de la constelación de fuerzas de poder existentes. Es posible no plegarse a los hechos desde la fuerza interior, y no en virtud de la idealidad (que, al final, revierte en los «ideales ascéticos»), sino por la fuerza de la realidad, por la profundización en ella, por la voluntad de vida, de salud y de poder.

El hombre no está aún agotado: del hombre podrían sacarse aún nuevas posibilidades, si se atreve a no seguir por los derroteros de la degeneración moderna que ha ido conformando al animal de rebaño ${ }^{27}$. «El superhombre es el sentido de la tierra», pues la figura (o metáfora) del superhombre invita a la superación del hombre e impulsa a la transfiguración de la existencia.

El hombre es «el animal aún no fijado» ${ }^{28}$. Hasta ahora se ha intentado «mejorar» al hombre mediante la «moral»; con esta se ha domado al hombre, se lo ha enfermado y degenerado, se lo ha debilitado en sus instintos vitales más profundos. Pues todos los medios con los que se ha pretendido mejorar al hombre han sido «inmorales» ${ }^{29}$. A juicio de Nietzsche, hay que recuperar el «orden natural» y «el arte supremo de la vida»; pero «la ley suprema de la vida» es la «jerarquía»,

24. KGW VIII/3: 14[133], «Anti-Darwin» (primavera de 1888) (FP IV 568-569).

25. CI, pp. 114-115; KGW VIII/2 10[82] y 10[61] (FP IV 324-325 y 319).

26. Paul Valadier, Nietzsche y la crítica del cristianismo, Madrid: Cristiandad, 1982, p. 162, n. 203.

27. MBM $\$ 203$ y Za, Prólogo $\mathbb{S} 3$ y 4.

28. MBM $\$ 62$.

29. CI, «Los 'mejoradores' de la humanidad». 
porque es la naturaleza la que separa, ya que «en su especie de ser tiene cada uno su privilegio», de tal manera que los que «dominan» lo hacen porque «son», porque pueden. La cultura conforme a la ley de la vida está regida por su jerarquía natural y vital ${ }^{30}$. Así que cada uno habrá de llegar a ser lo [o el] que es, según su cualidad de ser en plenitud ( $\dot{¿} \ll$ llegar a ser libre», llegar ser sí mismo, con cierto sentido del perfeccionamiento en el proceso de autosuperación?).

\section{NUEVA ILUSTRACIÓN}

Según el Nietzsche de la época tardía, habría una «nueva ilustración» ${ }^{31}$, una nueva forma de entender la ilustración —-más allá de la forma moderna del «espíritu libre»—que sí nos ofrecería la posibilidad de una nueva forma de progreso, el progreso tal como Nietzsche lo entiende y que es la que expone en Crepúsculo de los ídolos.

En el primero de los fragmentos en los que Nietzsche alude a «la nueva ilustración» presenta tres momentos fundamentales, el tercero de los cuales es «la superación del hombre» («la autosuperación como nivel de la superación del hombre») ${ }^{32}$. Además de referirse de nuevo a la autosuperación del hombre (la educación del hombre superior $)^{33}$, el siguiente fragmento introduce dos novedades muy significativas:

1) La conexión entre la nueva ilustración y el pensamiento del «eterno retorno", que precisamente constituirá uno de los problemas básicos de la filosofía nietzscheana: el de la relación del eterno retorno con la forma ilustrada y liberadora de entender la historia humana.

2) La otra novedad que aparece en este fragmento es la contraposición explícita con la «vieja» ilustración, debido a que la tendencia de la vieja ilustración se dirige hacia la «igualación de todos»y, por tanto, acaba en el «rebaño democrático». En cambio, el sentido de la nueva ilustración es también el de una nueva liberación, la de aquellas «naturalezas dominadoras» a las que les está permitido por su superior capacidad lo que no les está permitido (por su incapacidad) a los seres gregarios: una serie de ilustraciones que permiten la «autosuperación del hombre», es decir, «la educación del hombre superior». A la nueva ilustración le corresponde una nueva forma de liberación y de progreso del hombre. Y de ahí que, para Nietzsche, quepa (siempre) una renovada esperanza.

\section{1. ¿Progreso mediante selección?}

La filosofía de Nietzsche estuvo impulsada por el darwinismo, aun cuando Nietzsche no fue darwinista, sino - como es sabido- un evolucionista al estilo de Lamarck. Este antidarwinismo de Nietzsche provenía en el fondo, a mi juicio,

30. AC $\$ \$ 56$ y 57.

31. FP III 27[79] y 27[80], del verano-otoño de 1884 (Madrid: Tecnos, 2010, pp. 630 y 631). Cf. H. Ottmann, «Nietzsches Stellung zur antiken und modernen Aufklärung», en J. Simon (ed.), Nietzsche und die philosophische Tradition, vol. 2, Würzburg: Königshausen \& Neumann, 1985, pp. 9-33.

32. FP III 630-631: 27[79], verano-otoño de 1884.

33. FP III 631: 27[80], verano-otoño de 1884. 
de una concepción diferente de la naturaleza. Por eso, cuando Nietzsche caracteriza en Crepúsculo de los ídolos su peculiar forma de entender el progreso como «vuelta a la naturaleza», habrá que hacerlo no al estilo de la concepción biológica darwinista, porque esta supone un «regreso» y no un «progreso", ya que el auténtico progreso significa un ascenso: «ascender (binaufkommen) a la naturaleza», es decir a la naturalidad elevada, libre, terrible, que juega ${ }^{34}$.

$\mathrm{Al}$ parecer era esta concepción de la naturaleza la que también defendió Rol$\mathrm{ph}^{35}$ contra Spencer (Data of Ethics) ${ }^{36}$, insistiendo en que el desarrollo evolutivo no proviene de la necesidad (Not) o del «hambre» sino de la «abundancia» (Abundanz). En un sentido semejante, para Nietzsche, la existencia y la supervivencia no son la meta de la «voluntad de poder», sino que la dinámica de la voluntad de poder tiende a más, a la abundancia (Überfluss), a la plenitud e incluso al derroche. Este sentido antidarwiniano de la vida es el que se encuentra también en Crepúsculo de los ídolos, cuando critica «la famosa lucha por la vida» ${ }^{37}$, porque, según Nietzsche, «[la lucha por la vida] se da, pero como excepción; el aspecto de conjunto de la vida no es la situación calamitosa, la situación de hambre, sino más bien la riqueza, la exuberancia, incluso la prodigalidad absurda, — donde se lucha, se lucha por el poder...». Es esta una concepción antidarwiniana y antimalthusiana de la naturaleza ${ }^{38}$.

Pero en este texto que acabamos de citar, titulado «Anti-Darwin», Nietzsche critica también la concepción darwinista de la selección:

Pero suponiendo que esa lucha exista $-\mathrm{y}$ de hecho se da-, termina, por desgracia, al revés de como lo desea la escuela de Darwin, al revés de como acaso sería lícito desearlo con ella: a saber, en detrimento de los fuertes, de los privilegiados, de las excepciones afortunadas. Las especies no van creciendo en perfección: los débiles dominan una y otra vez a los fuertes, - es que ellos son el gran número, es que ellos son también más inteligentes... Darwin ha olvidado el espíritu (— ieso es inglés!), los débiles tienen más espíritu... ${ }^{39}$.

Nietzsche no acepta los presupuestos darwinistas de la selección (la supervivencia de los más fuertes y de los mejor dotados), sino que se opone a la selección darwinista, porque esta favorece el sentido gregario y la moral del rebaño.

Lo que más me sorprende al revisar los grandes destinos del ser humano es ver siempre ante mis ojos lo contrario de lo que hoy día Darwin y toda su escuela ven o quieren ver: la selección a favor de los más fuertes, de los mejor dotados, el progreso de la especie. Con las manos se toca justamente lo contrario: la supresión de los casos afortunados, la inutilidad de los tipos más altamente logrados, el

34. CI pp. 125-126; cf. FP IV 270-271: 9[116] (77).

35. En Biologische Probleme zugleich als Versuch einer rationellen Ethik, 1881.

36. Cf. KGW VII/3 247: 35[34], mayo-julio 1885 (FP III 780). Cf. H. Ottman, op. cit, p. 267, n. 112.

37. CI, «Incursiones de un intempestivo», $\mathbb{} 14$ «Anti-Darwin», p. 95.

38. Cf. la crítica nietzscheana de la «lucha por la vida» en J. Gayon, «Nietzsche and Darwin», en J. Maienschein y M. Ruse (eds.), Biology and the Foundations of Ethics, Cambridge, Cambridge University Press, pp. 154-197. Agradezco a Jean Gayon el envío de este trabajo y a Camilo J. Cela Conde su mediación.

39. CI, «Incursiones de un intempestivo», $\$ 14$ «Anti-Darwin», p. 95. 
inevitable dominio de los tipos mediocres, e incluso de los que están por debajo de la media ${ }^{40}$.

Esa voluntad de poder en la que yo vuelvo a reconocer la razón y el carácter últimos de toda alteración nos proporciona el medio de saber por qué precisamente la selección no se lleva a cabo en favor de las excepciones y de los casos afortunados: los más fuertes y los más felices son débiles cuando tienen en su contra los instintos de rebaño organizados, la pusilanimidad de los débiles, la superioridad numérica. Mi visión global del mundo de los valores muestra que [...] no predominan los casos afortunados, los tipos seleccionados: al contrario, los tipos de la décadence ${ }^{41}$.

La selección que defiende Nietzsche no es la «selección natural» de Darwin, sino la que tiene un sentido eugenésico. Nietzsche se enfrenta a la «selección natural» darwiniana. En los textos dedicados a la «selección» Nietzsche se refiere sobre todo a una selección voluntaria en el hombre, a lo que ya podría llamarse "eugenesia» (selección eugenésica) ${ }^{42}$. Según Gayon, Nietzsche consideró absurda la hipótesis de la existencia de un proceso natural que tuviera el propósito de la conservación de las especies: «la naturaleza no quiere conservar especies». Esta selección sería la que sirve a propósitos utilitarios y se basa en la mera «adaptación». Es más, en último término, esta presunta selección natural y utilitaria seguiría sometida al ideal de una especie humana «uniforme», «igualitaria»y "gregaria», una proyección en el campo de la historia natural de ciertos ideales morales, que, según Nietzsche, son más bien propios de una concepción "plebeya» y "cristiana» de la naturaleza, que al cabo resulta convergente con la darwiniana, por lo que se refiere a los valores que defiende, es decir, el valor moral del altruismo, de la compasión y de la autonegación, ahora sustentado en versión biológica, en el presunto orden natural de los instintos sociales ${ }^{43}$.

Nietzsche tenía otra idea de la selección, a partir de su nueva concepción de la naturaleza, otra idea del desarrollo moral y cultural, y, por tanto, ofrecerá también una nueva idea de "progreso", frente a la de Darwin, Spencer y el utilitarismo inglés, así como frente a judaísmo y cristianismo (tal como queda reflejado en La genealogía de la moral y Crepúsculo de los ídolos).

40. FP IV 561: 14[123].

41. FP IV 561: 14[123]; cf. también FP IV 568-569: 14[133], y FP IV 599-600: 14 [182].

42. J. Gayon, «Nietzsche and Darwin», cit., pp. 154-197.

43. Ibid., pp. 185 ss. En la nota 15, p. 194, Gayon remite al siguiente texto VP II 243. Pero cf. FP IV 299: 10[7](142): «Para reflexionar: hasta qué punto sigue existiendo la fatal creencia en la divina providencia - la creencia más paralizante que ha habido para la mano y para la razón-; hasta qué punto la presuposición y la interpretación cristianas perviven bajo las fórmulas 'naturaleza', 'progreso', 'perfeccionamiento', 'darwinismo', bajo la superstición de una cierta correspondencia entre felicidad y virtud, entre infelicidad y culpa. Esa absurda confianza en el curso de las cosas, en la 'vida', en el 'instinto de la vida', esa resignación bienpensante que está en la creencia de que basta con que cada uno haga su deber para que todo vaya bien - todo ese tipo de cosas solo tiene sentido bajo el supuesto de una conducción de la vida sub specie boni. Incluso el fatalismo, nuestra forma actual de sensibilidad filosófica, es una consecuencia de esa tan persistente creencia en la disposición divina, una consecuencia inconsciente: como si precisamente el modo en que marcha todo no dependiera de nosotros ( - como si nos estuviera permitido dejarlo suceder tal como sucede: cada individuo solo un modus de la realidad absoluta -). "Se le debe al cristianismo [...] la tonta confianza en el curso de las cosas (a 'mejor')». 
Precisamente en el tercer tratado de La genealogía de la moral Nietzsche critica el «ideal ascético» remitiendo explícitamente a la lucha por la vida en el sentido de Darwin, Spencer y el utilitarismo: «El ideal ascético nace del instinto de protección y de salud de una vida que degenera, la cual procura conservarse con todos los medios, y lucha por conservarse [...] El ideal ascético es una estratagema en la conservación de la vida $»^{44}$. Según Gayon, la palabra clave para interpretar la oposición de Nietzsche a Darwin, Spencer y el utilitarismo es «conservación». Nietzsche denunció una concepción de la vida y de la moral basada en la conservación (voluntad de sobrevivir), en vez de en el «aumento» (voluntad de poder). Aquí está la base de la nueva concepción nietzscheana del progreso, más allá del darwinismo. Nietzsche critica los valores morales subyacentes a la selección utilitaria y gregaria, porque, a su juicio, sigue favoreciendo a los débiles. Por tanto, no se trata de conservar la vida, sino de aumentar el poder.

\subsection{Eugenesia: ¿progreso biológico o progreso moral?}

Como hemos visto, la «selección» en Nietzsche no puede entenderse en el sentido de la «selección natural», sino en el de la selección humana, voluntaria, artificial, educativa (Zuchtwahl, Züchtung). El mismo Ottmann insiste en el «sentido moral» de la «cría» (Züchtung) en Nietzsche ${ }^{45}$, a pesar del innegable componente biológico que conlleva ${ }^{46}$. Lo que no tiene sentido es ocultarlo ni disfrazarlo, como se ha hecho, lo mejor es afrontarlo e interpretarlo en sus justos términos del modo más adecuado.

Es sabido que en los años ochenta aumenta el interés de Nietzsche por la fisiología, convirtiéndola en «señora de todas las otras cuestiones». No obstante, esto no implica que Züchtung no pueda tener un sentido moral, ligado a la formación (Bildung) y la educación (Zucht). Más bien, hay que incorporar este sentido de los términos en el contexto de la "gran política»" ${ }^{47}$ que no ha de entenderse como una mera operación biológica, sino como una educación del hombre a través de una nueva formación moral. «Las morales legisladoras son el medio principal con que formar a partir del hombre lo que una voluntad creadora y profunda desee» ${ }^{48}$. ¿No se trata de un nuevo medio educativo de la voluntad creadora? Pero, ¿cuál es el nuevo medio educativo, según Nietzsche? El pensamiento selectivo (criador) del «eterno retorno», el nuevo "centro de gravedad», la educación para la afirmación de la vida y del más acá. Una nueva paideia, una «guerra de los espíritus», la «cría»". Indudablemente, la fisiología —entendida al modo nietzscheano- está en el trasfondo de la gran política y de la formación de la voluntad creadora.

44. GM III $\$ 13$, p. 140.

45. H. Ottmann, op. cit., pp. 262 ss.

46. CI, «Incursiones», $\mathbb{3} 36$. Sobre la conexión con F. Galton (sentido bilógico y más allá), cf. los trabajos citados de Gayon y Ottmann. También T. H. Brobjer, «Züchtung», en H. Ottmann (ed.), Nietzsche-Handbuch, Stuttgart: Metzler, 2000, pp. 360-361; y "Nietzsche's Reading and Private Library, 1885-1889»: Journal of the History of Ideas 58/4 (1997), pp. 663-693.

47. Cf. J. Conill, op. cit., parte III.

48. FP III 814: 37[8].

49. $\mathrm{EH}$ «Por qué soy un destino», $\mathbb{1} 1$ p. 124 ; $\mathrm{CI}$ «La moral como contranaturaleza», $\mathbb{3} \mathrm{y}$ «Los 'mejoradores' de la humanidad", pp. 72-75. 
La tarea pendiente de formar al hombre tras la «muerte de Dios» conduce a Nietzsche a una posición cuasi prometeica, que viene expresada en su traducción del Theages y que resulta esclarecedora para interpretar la noción nietzscheana de los «señores de la tierra»: «todos nosotros desearíamos ser señor, a ser posible, de todos los hombres, preferiblemente Dios. Tiene que volver a existir esa actitud ${ }^{50}$.

El problema surge cuando se aplica el esquema darwiniano, es decir, cuando se pretende vincular la idea de una «especie superior», que constituiría un novum en la historia de la evolución, con la doctrina del «eterno retorno de lo mismo». Pero esta aporía puede solventarse, porque, para Nietzsche, podría haber un novum en el eterno retorno. En el retorno nietzscheano puede haber progreso mediante la noción nietzscheana de «superhombre». No habría ninguna irreconciliable oposición entre la doctrina del eterno retorno y el superhombre.

Lo que retorna es una cierta selección, pero no de carácter darwinista, sino eugenésico, la «selección» que expresa la figura del superhombre. E inmediatamente se plantea la cuestión de si tiene carácter biológico y/o moral, y surgen las correspondientes consecuencias educativas. A pesar de ciertas expresiones del propio Nietzsche, el superhombre no ha de identificarse con una especie, sino que es una metáfora para las posibilidades que se le abren al hombre, pero que son realizadas por los individuos. El ideal de Nietzsche siempre ha sido el de la «grandeza» del individuo ${ }^{51}$.

El «superhombre» era expresión de una esperanza y constituye solo un lado de la doctrina del retorno, pues el hombre «pequeño» o «último» también puede retornar. Lo que ocurre es que la doctrina del superhombre en la primera parte del Zaratustra ha provocado interpretaciones darwinistas y progresistas, pero hay que llegar a la tercera parte, donde se revela la decisiva doctrina del eterno retorno, que hay que combinar necesariamente con la del superhombre. Sin haber incorporado el pensamiento del eterno retorno, cabría interpretar la secuencia «mono-hombre-superhombre» como si fuera una progresión darwinista. Tras la doctrina del eterno retorno, hay que situarse ante una forma nueva de entender el tiempo como tiempo de decisión entre el «último hombre» y el «superhombre». No hay un final de la historia, que resuelva este enigma, pues ambos son parte de un acontecer en el que todo retorna ${ }^{52}$. ¿A qué nos conduce Nietzsche propiamente, a aceptar los resultados de la evolución, o bien a plantearnos la necesidad de una decisión, es decir, de una resolución?

Nietzsche no ha expuesto nunca con total claridad la figura del superhombre $^{53}$. Incluso la referencia a los «nuevos señores de la tierra» como sus precursores es oscura, pero alguna de sus expresiones alumbra un nuevo sentido de «progreso»: «El superhombre, el transfigurador de la existencia ${ }^{54}$. Por otra parte, el superhombre no puede entenderse como mero producto biológico, sino un

50. FP III 481: 25[137].

51. FP IV 670: 15[120]; FP IV 551: 14[110]. Cf. J. Conill, El enigma del animal fantástico, Madrid: Tecnos, 1991.

52. Cf. Za, «El convaleciente», pp. 297 ss.; también «De la visión y del enigma», pp. 223 ss. Cf. H. Ottmann, op. cit., p. 269.

53. Cf. M.-L. Haase, «Der Übermensch in 'Also sprach Zarathustra' und im Zarathustra-Nachlass 1882-1885»: Nietzsche-Studien 13 (1984), pp. 242 ss.

54. FP III 790: 35[73] 
golpe de suerte, de fortuna, un caso fortuito (Glücksfall), un efímero chispazo de "grandeza», como el genio, muy arriesgado y complicado, mientras que la evolución favorece lo no complicado. No basta la evolución (la selección natural), sino que hace falta la formación con base fisiológica para lograr una eugenesia (liberadora, meliorativa, superadora).

Por tanto, el superhombre no es un mero producto del progreso evolutivo ${ }^{55}$ (y menos en el sentido del darwinismo y del progresismo), sino que su formación (Bildung), sea como autosuperación moral, sea como creación artística, está más allá de lo meramente biológico. Así pues, el progreso en el sentido en que lo entiende Nietzsche consiste en un ascenso a la naturaleza, que no ha de confundirse con la «vuelta a la naturaleza» propugnada por Rousseau, ni con su «moralidad», ya que Nietzsche rechaza sus valores morales modernos y las presuntas «verdades» de la Revolución, en especial, «la doctrina de la igualdad» $»^{56}$, porque —además de ser un «veneno»- implica el final de la auténtica «justicia» y no es el camino para llegar a ser libre, conforme al prototipo que propone Nietzsche aludiendo a Goethe: el «espíritu que ha llegado a ser libre», sin desligarse de la vida y, por tanto, siendo un «realista» vital ${ }^{57}$.

El progreso en el sentido nietzscheano pasa a través del pensamiento selectivo o criador del eterno retorno, que tiene un sentido eugenésico de selección vital humana mediante la transvaloración de los valores vitales y con un sentido aristocrático, que Nietzsche ha expresado durante cierta etapa de su producción mediante la figura — ni optimista ni pesimista, sino seguramente trágica- del «superhombre», como parte de un acontecer liberador que siempre puede retornar.

55. FP IV 568-569: 14 [133]

56. «Igualdad para losiguales, desigualdad para los desiguales—esesería el verdaderodiscurso dela justicia: y, lo que de ahíse sigue, noigualar jamás a los desiguales». Cf.Za, «Delastarántulas», pp. 151-154.

57. CI, pp. 125-126 y MBM, p. 197. Cf. G. Campioni, «Von der Auflösung der Gemeinschaft zur Bejahung des 'Freigeistes'»: Nietzsche-Studien 5 (1976), 83-113. 